\title{
Berengeria rafaeli, gen. nov., sp. nov. de Reduviinae da Reserva Ducke, Estado do Amazonas, Brasil (Hemiptera-Heteroptera, Reduviidae).
}

\author{
Hélcio R. GIL-SANTANA ${ }^{1}$; Alexandre COLETTO-SILVA²
}

\section{RESUMO}

Um novo gênero e espécie de Reduviinae (Hemiptera-Heteroptera, Reduviidae) do Estado do Amazonas, Brasil, são descritos. Uma chave taxonômica para os gêneros Americanos de Reduviinae é fornecida.

\section{PALAVRAS-CHAVE}

Reduviinae, Neotropical, Amazônia.

\section{Berengeria rafaeli, n. gen., n. sp. of Reduviinae from Reserva Ducke, Amazonas State, Brazil (Hemiptera- Heteroptera, Reduviidae).}

\begin{abstract}
A new genus and species of Reduviinae (Hemiptera-Heteroptera, Reduviidae) from the Amazonas State, Brazil are described. A taxonomic key for American genera of Reduviinae is given.
\end{abstract}

\section{KEYWORDS}

Reduviinae, Neotropical, Amazon.

\section{INTRODUÇÃO}

Ao estudar-se um Reduviídeo pertencente à subfamília Reduviinae, coletado na Reserva Ducke ( $\left.02^{\circ} 55^{\prime} \mathrm{S} 50^{\circ} 59^{\prime} \mathrm{W}\right)$, próximo à cidade de Manaus, Estado do Amazonas, Brasil, constatou-se tratar de um espécime pertencente a gênero e espécie novos, os quais são descritos no presente trabalho.

A subfamília Reduviinae, até recentemente, era representada por 16 gêneros no Novo Mundo: Aradomorpha Champion, 1899, Corupaia Lent \& Wygodzinsky, 1948, Leogorrus Stål, 1859, Microlestria Stål, 1872, Nalata Stål, 1860, Namapa Wygodzinsky \& Lent, 1980, Neivacoris Lent \& Wygodzinsky, 1947, Opisthacidius Berg, 1879, Pantopsilus Berg, 1879, Patago Bergroth, 1905, Peregrinator Kirkaldy, 1904, Pseudozelurus Lent \& Wygodzinsky, 1947, Reduvius Fabricius, 1775, Sinnamarynus Maldonado Capriles \& Bérenger, 1996, Zeluroides Lent \& Wygodzinsky, 1948 e Zelurus Hahn, 1826 (Gil-Santana \& Jurberg, 2002).
Entre os gêneros de Reduviinae, Berengeria gen. nov. é mais próximo de Nalata Stål, 1860, cuja espécie-tipo é Nalata aspera Stål, 1860, por designação subseqüente de Wygodzinsky (1949).

Nalata aspera foi descrita a partir de um único macho, procedente do Rio de Janeiro (Stål, 1860), que permanece depositado na Coleção C. Stål do Museu de Estocolmo, Suécia.

Atualmente estão incluídas dez espécies em Nalata, seis das quais conhecidas da América Central, duas da América do Sul e outras duas de ambas as regiões. No Brasil, já foram assinaladas, além da espécie-tipo, Nalata fuscipennis Stål, 1860 (Lethierry \& Severin, 1896; Champion, 1899; Wygodzinsky, 1949; Puthskov \& Putshkov, 1985; Maldonado Capriles, 1990) e Nalata setulosa Stål, 1862 (Gil-Santana \& Zeraik, 2002).

Berengeria gen. nov. possui ainda caracteres que, isoladamente, só são encontrados de forma semelhante em

\footnotetext{
${ }^{1}$ Laboratório de Diptera, Instituto Oswaldo Cruz, Av. Brasil, 4365, Manguinhos, CEP 21045-900 Rio de Janeiro, Rio de Janeiro, Brasil. E-mail: helciogil@uol.com.br ${ }^{2}$ Grupo de Pesquisas em Abelhas, Coordenação de Pesquisas em Ciências Agronômicas, Instituto Nacional de Pesquisas da Amazônia, Av. André Araújo, 2936, Petrópolis CEP 69083-000, Caixa Postal 478, Manaus, Amazonas, Brasil. Fone: (92) 64332816423440 . E-mail: alexbelha@ hotmail.com
} 
outros gêneros, como Microlestria e Peregrinator, dos quais, contudo não é aproximado, como comentado adiante.

Apresenta-se, a seguir, uma chave para gêneros de Reduviinae das Américas, baseada numa chave anterior de Bérenger et al. (1996):

1. Genas laminadas e alongadas, incluindo entre elas a base do rostro; inserção das antenas laterais.

Aradomorpha Champion, 1899

1'.Genas diferentes; inserção das antenas dorsais........... 2

2. Ausência de fossas esponjosas nas tíbias...................... 3

2'. Presença de fossas esponjosas nas tíbias........................6

3. Comprimento superior a $20 \mathrm{~mm}$. Pernas longas e delgadas Patago Bergroth, 1905

3'.Comprimento inferior a $10 \mathrm{~mm}$. Pernas curtas............. 4

4. Membrana do hemiélitro com uma única célula, tarsos trímeros. Microlestria Stål, 1872

4'. Membrana do hemiélitro com duas células, tarsos dímeros.

5. Face inferior dos trocânteres anteriores com um espinho...Nalata Stål, 1860

5'.Face inferior dos trocânteres anteriores inermes Berengeria gen. nov.

6. Ápice da face inferior de todos os fêmures com um par de pequenos dentes Leogorrus Stål, 1859

6'.Ápice da face inferior de todos os fêmures sem pares de dentes.

7. Disco do lobo anterior do pronoto inerme................. 8

7'. Disco do lobo anterior do pronoto armado com tubérculos ou espinhos... 14

8. Face inferior dos fêmures anteriores e médios armados com dentes em toda sua extensão. .... 9

8'. Face inferior dos fêmures anteriores e médios sem dentes em toda sua extensão. .. 10

9. Cabeça alongada, cerca de dez vezes mais longa do que larga; olhos muito pequenos, pouco salientes. Comprimento superior a $15 \mathrm{~mm}$ Pantopsilus Berg, 1879

9'. Cabeça tão longa quanto larga; olhos grandes, salientes. Comprimento: $11 \mathrm{~mm}$. Sinnamarynus Maldonado Capriles \& Bérenger, 1996

10. Espécies de pequeno comprimento, de 6 a $8 \mathrm{~mm}$......11

10'. Espécies com comprimento superior a $10 \mathrm{~mm}$.......... 12

11. Corpo com longos pêlos eriçados. Ângulos dos segmentos do conexivo não são salientes................................... Peregrinator Kirkaldy, 1904

11'. Corpo desprovido de longos pêlos. Ângulos dos segmentos do conexivo salientes............... Namapa Wygodzinsky \& Lent, 1980

12. Face inferior dos fêmures anteriores com um sulco longitudinal e duas fileiras de numerosos pequenos pêlos curtos. As duas células da membrana da asa com dimensões aproximadamente iguais.....Corupaia Lent \& Wygodzinsky, 1948

12'. Face inferior dos fêmures anteriores unicamente com pêlos simples, sem sulco longitudinal. Células interna e externa da membrana de tamanho diferentes................................... 13

13. Célula externa da membrana maior que a interna............................................ Reduvius Fabricius, 1775

13'. Célula externa da membrana de dimensões inferiores à célula interna............. Pseudozelurus Lent \& Wygodzinsky, 1947

14. Pronoto nitidamente granuloso............................... 15

14'.Pronoto sem granulações............................................ 16

15. Disco do lobo anterior do pronoto com quatro tubérculos. Fêmures anteriores e médios muito mais engrossados que os fêmures posteriores....... Opisthacidius Berg, 1879

15'. Disco do lobo anterior do pronoto com um par de tubérculos ou de espinhos curtos. Todos os fêmures delgados.............................................Zeluroides Lent \& Wygodzinsky, 1948

16. Jugas muito desenvolvidas, alcançando ou ultrapassando o ápice da cabeça; clípeo vertical.......................... Neivacoris Lent \& Wygodzinsky, 1947

16'. Jugas pouco salientes, não alcançando o ápice da cabeça; clípeo jamais vertical................................. Zelurus Hahn, 1826

\section{Berengeria gen. nov.}

Diagnose. Superfície corporal rugosa com pêlos longos, finos, esparsos, eriçados, amarelados a prateados.

Cabeça (Fig. 1) subtriangular, com olhos e ocelos pequenos e bastante afastados entre si. Clípeo com espinho dorsal pouco desenvolvido e de base larga. Inserção das antenas protegidas lateralmente por um pequeno esclerito. Em vista lateral, observam-se duas elevações, uma na região ocelar e outra na fronte, sobre os olhos; na região ínfero-posterior observa-se nítido tubérculo dirigido para trás.

Tórax (Fig. 1). Pronoto: sulco mediano longitudinal bem profundo na porção mediana do mesmo. Lobo anterior bem mais estreito que o posterior (Fig. 1). Lobo anterior com um par de espinhos conspícuos na região central e outro pequeno lateral. Ângulos humerais arredondados. Escutelo subtriangular; na parte central observa-se um par de depressões arredondadas; nas margens laterais há um espinho rombo próximo à base e oápice é dilatado e arredondado. Fêmures apresentando a face dorsal com granulosidade formada por grânulos pequenos; têm ligeira dilatação subapical em todos os pares de pernas, menos evidente, porém no par posterior. Tíbias cilíndricas; as anteriores um pouco mais espessadas, com dilatação apical proeminente; ausência de fossa esponjosa em todas elas. Tarsos dímeros. Hemiélitros com duas células grandes, de tamanho equivalente entre si (Fig. 1). A área do córioé relativamente reduzida em relação a da membrana, a qual ocupa mais de $2 / 3$ da área total do hemiélitro (Fig. 1).

Abdome: conexivo bem saliente e borda lisa, com exceção do primeiro segmento que apresenta espinho conspícuo, de formato triangular (Fig. 1). 


\section{ACTA AMAZONICA}

Etimologia. O nome do novo gênero foi dado em homenagem ao entomologista francês, Jean-Michel Bérenger, por toda a contribuição que tem feito ao estudo dos Reduviidae.

\section{Berengeria rafaeli sp. nov.}

Descrição. Fêmea (Fig. 1).

Dimensões (em mm) - Corpo: comprimento: 3,8 até o ápice dos hemiélitros e 3,5 até o ápice do abdome. Cabeça: comprimento: 0,8 ; largura entre os olhos: 0,$4 ;$ antena: segmento I: 0,5 ; segmento II: 0,6 ; demais segmentos perdidos. Tórax: comprimento do pronoto: 0,7 ; largura do lobo anterior do pronoto: 0,$7 ;$ largura do lobo posterior do pronoto: 1,1 ; pernas anteriores: fêmur: 0,9 ; tíbia: 0,9 ; tarso: ausente; pernas médias: fêmur: 0,9 ; tíbia: 0,9 ; tarso: 0,3 ; pernas posteriores: fêmur: 1,3 ; tíbia: 1,3 tarso: 0,4 . Abdome: comprimento: 1,7; largura: 1,7.

Coloração geral castanho-avermelhada com áreas mais claras no cório dos hemiélitros.

Cabeça avermelhada, com tegumento fosco. Rostro com segmentos grossos, uniformes; o ápice alcançando a altura da região prosternal. Colo longo. Antenas mais claras com pêlos longos e finos. Segmento antenal I pouco dilatado na porção mediana; segmento II cilíndrico; restantes ausentes.

Tórax: tegumento fosco, com pêlos longos finos e claros, esparsos. Pleuras sem marcações. Pernas claras, amareladas, recobertas com pilosidade esparsa, clara, de pêlos longos e finos. Hemiélitros escurecidos com veias do cório e as regiões adjacentes a estas bem claras, amareladas. Membrana enegrecida com as nervuras amareladas. O cório apresenta pêlos longos, finos e claros muito esparsos, enquanto a membrana é glabra.

Abdome: conexivo amarelo-escurecido com pêlos longos, finos e claros; amarelo-escurecido; sutura intersegmentar destacando-se pela coloração branca. Esternitos com tegumento liso, glabro, brilhante e de coloração pardoavermelhada. Região genital levemente mais escurecida com pêlos longos e finos a esse nível.

Holótipo fêmea. BRASIL. AMAZONAS. Reserva Ducke, Rodovia AM 010, $\mathrm{Km} 26$ ao Norte de Manaus, $02^{\circ} 55^{\prime} \mathrm{S} 50^{\circ} 59^{\prime} \mathrm{W}$, 27.VIII.1982, J. A. Rafael leg., Armadilha Malaise.

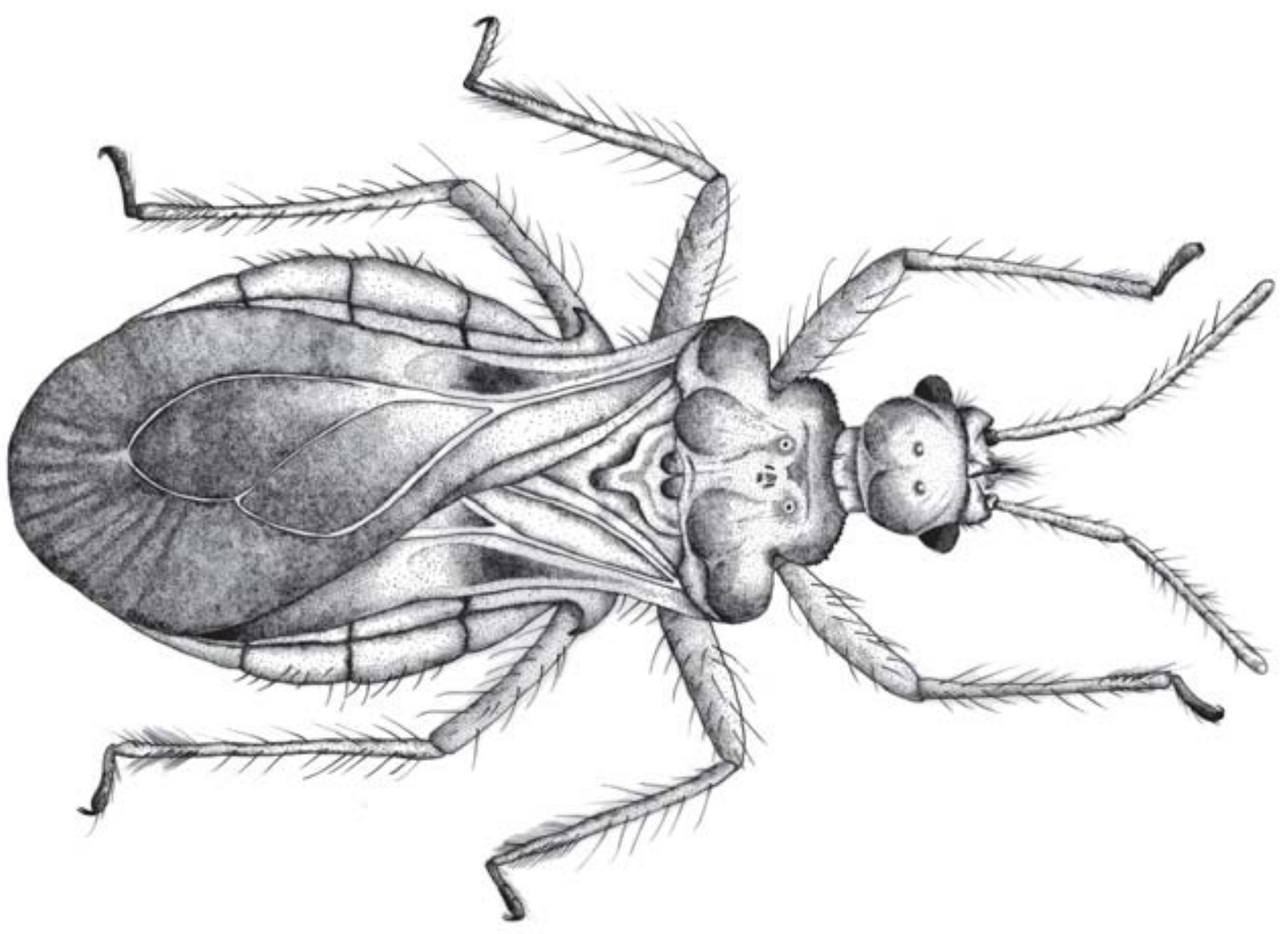

Figura 1 - Berengeria rafaeli n. gen., n. sp., holótipo, fêmea, vista dorsal. - Berengeria rafaeli n. gen., n. sp., holotype, female, dorsal view. 


\section{ACTA AMAZONICA}

BERENGERIA RAFAELI, GEN. NOV., SP. NOV. DE REDUVIINAE DA RESERVA DUCKE, ESTADO DO AMAZONAS, BRASIL (HEMIPTERA-HETEROPTERA, REDUVIIDAE).
Etimologia. O nome da espécie é dado em homenagem ao coletor do holótipo da mesma, o entomologista e pesquisador do INPA, Dr. José Albertino Rafael.

\section{DISCUSSÃO}

Nalata é o gênero mais próximo de Berengeria gen. nov., cujos principais caracteres em comum são os constantes da chave apresentada.

A coloração dos élitros e a presença de pêlos longos e eriçados no tegumento de Berengeria rafaeli gen. nov., sp. nov. são superficialmente semelhantes ao apresentado pela única espécie de Peregrinator, P. biannulipes (Montrouzier \& Signoret, 1861).

Por outro lado, a redução relativa da área do cório em relação a da membrana é encontrada também nas espécies de Microlestria .

Berengeria rafaeli gen. nov., sp. nov. é uma das espécies de menores dimensões entre os Reduviinae americanos e apresenta caracteres muito particulares, tais como: a forma da cabeça; o afastamento dos olhos e ocelos entre si; a presença de um pequeno esclerito lateral na inserção das antenas; as duas elevações, uma na região ocelar e outra na fronte, sobre os olhos; o tubérculo da região ínfero-posterior da cabeça e os espinhos laterais do primeiro segmento abdominal.

\section{AGRADECIMENTOS}

Ao Prof. Dr. Augusto Henriques, Curador da Coleção Entomológica do INPA pelo empréstimo do holótipo ora descrito; Prof. Bert Gustaffson, do Museu de Estocolmo, por fornecer informações sobre o holótipo de Nalata aspera, depositado naquela Instituição.

\section{BIBLIOGRAFIA CITADA}

Berénger, J.-M.; Maldonado Capriles, J.; Pluot-Sigwalt, D. 1996. Un noveau genre de Reduviinae de Guyane et notes sur la sous-famille (Heteroptera, Reduviidae). Bull. Soc. Entomol. France 101(3): 251-256.

Champion, G. C., 1899 - Insecta Rhynchota. HemipteraHeteroptera, Vol II. p. 229-243. In: Godman, F. D.; Salvin, O. (eds.). Biologia Centrali Americana. Rhynchota. London, XIV + 416 pp., 2 pls.

Gil-Santana, H. R.; Jurberg, J. 2002. Descrição da fêmea de Corupaia brasiliensis Lent \& Wygodzinsky, 1948 (Hemiptera: Reduviidae: Reduviinae). Entomol. Vect., 9(4): 519-526.

Gil-Santana, H. R.; Zeraik, S. O. 2002. Reduviidae de Nova Friburgo, Estado do Rio de Janeiro, Brasil (HemipteraHeteroptera). Entomol. Vect., 9(2): 295-299.

Lethierry, L.; Severin,. G. 1896. Catalogue général des Hémiptères. Berlin. Tome III. 275 pp.

Maldonado Capriles, J. 1990. Systematic Catalogue of the Reduviidae of the World (Insecta: Heteroptera). Caribbean J. Sci., (special ed.), Mayagüez. 694 pp.

Putshkov, V. G.; Putshkov, P. V. 1985. A Catalog of Assassin-Bug Genera of the World (Heteroptera, Reduviidae). [Published by the authors], Kiev. 137pp.

Stål, C. 1860. Bidrag till Rio de Janeiro-traktens Hemipter-fauna. I. K. Vet.-Akad. Handl. 2(7): 1-84.

Wygodzinsky, P. 1949. Elenco sistematico de los reduviiformes americanos. Inst. Med. Reg. Tucumán, Monografia 1:1-102.

\section{RECEBIDO EM 01/09/2004 ACEITO EM 02/06/2005}

